\title{
COLD AGGLUTININS. VI. AGGLUTININS FOR AN INDIFFERENT STREPTOCOCCUS IN PRIMARY ATYPICAL PNEUMONIA AND IN OTHER CONDITIONS AND THEIR RELATION TO COLD ISOHEMAGGLUTININS
}

\author{
By MAXWELL FINLAND, BERNARDO A. SAMPER, AND MILDRED W. BARNES \\ (From the Thorndike Memorial Laboratory, Second and Fourth Medical Services (Harvard), \\ Boston City Hospital, and the Department of Medicine, Harvard Medical School, Boston)
}

(Received for publication September 22, 1944)

The isolation of an indifferent streptococcus (Number 344) from the lung of a fatal case of primary atypical pneumonia has recently been reported (1) and its biological properties described. Convalescent sera from more than onehalf of the cases of atypical pneumonia which were tested agglutinated this strain in final dilutions ranging from $1: 10$ to $1: 160$ whereas agglutination in low titers occurred only rarely in the acute phase sera of such cases, in sera of normal individuals, or in acute or convalescent sera from persons with other respiratory diseases. The results of the streptococcal agglutination tests in atypical pneumonia correlated in many instances with the results of cold hemagglutination tests and with complement fixation tests with mouse lung antigen (2). In a number of cases, however, positive results were obtained with only one or two of these tests. Similar strains were also isolated from other cases.

The authors did not feel that their evidence warranted the conclusion that the bacterium is a factor in the etiology of primary atypical pneumonia. Nevertheless, the fact that the positive findings were restricted largely to cases of atypical pneumonia is of some interest. The present paper deals with the results of serological tests in cases of atypical pneumonia and of other conditions using streptococcus 344 and another similar strain (E. S.) isolated in this laboratory. Tests for cold hemagglutinins were also done in all of the sera included in this study.

\section{MATERIALS AND METHODS}

A total of 255 sera from 78 cases of atypical pneumonia and 330 sera from 163 other individuals were used in this study. The latter include serial specimens from 6 cases of rheumatic fever and 82 individual sera from non-rheumatic carriers and non-carriers of hemolytic streptococci. All of the rheumatic patients and a number of the others had recent streptococcal infections. The antistreptolysin titers of these sera were known. The sera and the antistreptolysin data were generously provided by Drs. T. Duckett Jones and Benedict F. Massell, of the House of the Good Samaritan, who had carried out repeated throat cultures in these cases. Antistreptolysin determinations were also carried out in their laboratory on serial specimens from a number of the cases of atypical pneumonia. The sera in the atypical pneumonias were tested after they had been stored from 3 to 15 months. All but a few of the remaining sera were tested within a few weeks of the time they were obtained.

Streptococcal agglutinations were carried out in essentially the manner described by Thomas et al. (1). A transplant of strain 344 was obtained from Dr. Thomas and strain E. S. was isolated in December 1943 from a sputum obtained late in the disease in a characteristic and severe case of atypical pneumonia. It was found in almost pure culture in this sputum and it had cultural, biological, and serological properties similar to those of strain 344. The antigens were prepared by washing the sediment of broth cultures 3 times in saline and then resuspending it in saline in one-third of the original volume of the culture. The suspensions were then heated at $65^{\circ} \mathrm{C}$. for one-half hour and stored at $5^{\circ} \mathrm{C}$. when not in use. For the tests, equal volumes of the antigens and of serial dilutions of serum, beginning $1: 5$, were incubated for 18 hours at $37^{\circ} \mathrm{C}$. before reading. The positive sera gave floccular agglutinations similar to those obtained with pneumococci. Some of the control sera gave a finely granular type of agglutination in the lowest dilutions and these were visible only with the aid of a magnifying lens. The titers were read as the reciprocal of the highest final dilution of serum giving floccular agglutination. The method used in the cold hemagglutination tests is described in a previous paper (3).

\section{RESULTS}

The number of cases in each of the various groups studied and the maximum titers of agglutinins obtained in the cases of each group, both with strain 344 and with strain E.S., are shown in Table I. It is seen at a glance that the maximum titers in cases of primary atypical pneumonia differed from those found in each of the other 
groups. Titers of 40 or higher were obtained in about one-half of the cases of atypical pneumonia when strain 344 was used and in about threefourths of the cases when strain E. S. was used. Such titers were obtained in only 5 per cent or less of the cases in the other groups with either of the two strains. In general, the agglutination which occurred in the sera of cases other than atypical pneumonia were qualitatively less marked than were the agglutinations that occurred in similar dilutions of sera from cases of atypical pneumonia. Furthermore, the development of agglutinins for the indifferent streptococci and the occurrence of rises in titer or of increases in the intensity of the agglutination during the course of the disease or in convalescence was limited almost entirely to the cases of atypical pneumonia.

Before considering the results in the cases of atypical pneumonia a few of the relevant features of some of the other cases of interest, particularly those in which the maximum titers of streptococcal agglutinins was 40 or higher, will be considered briefly.

In one of the normal subjects who did not have any respiratory infection and was not a carrier of hemolytic streptococcus, the titer of agglutinins was 320 for strain
344 and 1280 for strain E. S. These agglutinations were obtained in a single specimen of serum which was cloudy; the agglutinations were fluffy in all of the dilutions and the substrates were not clear as in other sera in which strong agglutination occurred. There were no cold hemagglutinins in this serum.

One of the cases listed among the non-respiratory infections was a case of fever of undetermined origin that lasted many weeks and failed to respond to sulfonamides, penicillin, salicylates, and non-specific therapy. The titers obtained in several sera in this case were all 40 with strain 344 and 20 or 40 with strain E. S. There were no cold agglutinins in any of this patient's sera.

Four of the cases of bacterial pneumonia are of interest. In one of them, a titer of 20 was obtained with both of the strains during the fourth and fifth week of the disease. Serum obtained during the seventh week gave a titer of 80 with strain 344 and 40 with strain E. S. This patient had type 7 pneumococcus pneumonia and a recurrent and prolonged bacteremia probably due to bacterial endocarditis. He recovered following intensive penicillin therapy. There were no cold agglutinins in any of his sera. In a second case, the titer with strain 344 rose from 20 to 80 and that for E. S. rose from 40 to 160 . This patient had a diffuse bronchopneumonia of both lower lobes; type 12 pneumococcus was obtained from the sputum; blood cultures were negative and the leukocyte count was 4,850 during the acute stage of the disease and rose to 14,000 later. He showed a very slow response to treatment with penicillin and may have had an underlying atypical pneumonia of non-bacterial etiology. Cold agglutinins, how-

TABLE I

Occurrence of agglutinins for two strains of indifferent streptococci in cases of primary atypical pneumonia associated with cold agglutinins and in various other conditions

\begin{tabular}{|c|c|c|c|c|c|c|c|c|c|c|c|}
\hline \multirow{3}{*}{ Diagnosis } & \multicolumn{10}{|c|}{ Maximum agglutinin titer } & \multirow{3}{*}{$\begin{array}{l}\text { Total } \\
\text { number } \\
\text { of cases }\end{array}$} \\
\hline & \multicolumn{5}{|c|}{ Streptococcus 344} & \multicolumn{5}{|c|}{ Streptococcus E.S. } & \\
\hline & $<10$ & 10 & 20 & 40 & $\begin{array}{l}80 \\
\text { or } \\
\text { higher }\end{array}$ & $<10$ & 10 & 20 & 40 & $\begin{array}{c}80 \\
\text { or } \\
\text { higher }\end{array}$ & \\
\hline Primary atypical pneumonia, all cases & 7 & 11 & 23 & 15 & 22 & 1 & 8 & 11 & 15 & 43 & 78 \\
\hline $\begin{array}{l}\text { Cold agglutinins: } 20 \text { to } 80 \\
\text { (Maximum titers) } 160 \text { to } 320 \\
640 \text { or higher }\end{array}$ & $\begin{array}{l}3 \\
3 \\
1\end{array}$ & $\begin{array}{l}5 \\
5 \\
1\end{array}$ & $\begin{array}{r}5 \\
11 \\
7\end{array}$ & $\begin{array}{l}4 \\
4 \\
7\end{array}$ & $\begin{array}{l}6 \\
7 \\
9\end{array}$ & $\begin{array}{l}1 \\
0 \\
0\end{array}$ & $\begin{array}{l}1 \\
6 \\
1\end{array}$ & $\begin{array}{l}6 \\
3 \\
2\end{array}$ & $\begin{array}{l}3 \\
4 \\
8\end{array}$ & $\begin{array}{l}12 \\
17 \\
14\end{array}$ & $\begin{array}{l}23 \\
30 \\
25\end{array}$ \\
\hline $\begin{array}{l}\text { Hemolytic streptococcal infections } \\
\text { Carriers without infection } \\
\text { Acute rheumatic fever } \\
\text { Subacute bacterial endocarditis }\end{array}$ & $\begin{array}{r}6 \\
17 \\
3 \\
3\end{array}$ & $\begin{array}{r}3 \\
13 \\
3 \\
1\end{array}$ & $\begin{array}{l}1 \\
3 \\
1\end{array}$ & 1 & & $\begin{array}{r}7 \\
21 \\
4 \\
3\end{array}$ & $\begin{array}{l}2 \\
9 \\
1 \\
1\end{array}$ & $\begin{array}{l}1 \\
3 \\
1 \\
1\end{array}$ & 1 & & $\begin{array}{r}10 \\
33 \\
6 \\
6\end{array}$ \\
\hline $\begin{array}{l}\text { Bacterial pneumonia } \\
\text { Influenza A } \\
\text { Other respiratory infections }\end{array}$ & $\begin{array}{r}17 \\
11 \\
6\end{array}$ & $\begin{array}{l}5 \\
1 \\
1\end{array}$ & $\begin{array}{l}5 \\
1\end{array}$ & & 2 & $\begin{array}{r}15 \\
11 \\
6\end{array}$ & $\begin{array}{l}4 \\
1\end{array}$ & $\begin{array}{l}6 \\
1 \\
1\end{array}$ & 3 & 1 & $\begin{array}{r}29 \\
13 \\
7\end{array}$ \\
\hline $\begin{array}{l}\text { Non respiratory infections } \\
\text { Normal (non-strep. carriers) } \\
\text { Hemolytic anemia (no pneumonia) } \\
\text { (cold agglutinins } 40 \text { to } 2560 \text { ) }\end{array}$ & $\begin{array}{r}11 \\
15 \\
4\end{array}$ & $\begin{array}{r}3 \\
15\end{array}$ & $\begin{array}{l}1 \\
8\end{array}$ & 1 & 1 & $\begin{array}{r}9 \\
19 \\
4\end{array}$ & $\begin{array}{r}6 \\
11\end{array}$ & 8 & & $\begin{array}{l}1 \\
1\end{array}$ & $\begin{array}{r}16 \\
39 \\
4\end{array}$ \\
\hline Total-not atypical pneumonia & 93 & 45 & 20 & 2 & 3 & 99 & 35 & 22 & 4 & 3 & 163 \\
\hline
\end{tabular}


ever, were not obtained in any of the sera in this case. In a third case, streptococcal agglutinins were not demonstrated during the acute phase and titers of 20 and 40 were obtained with strains 344 and E. S., respectively, early in convalescence. The patient had diffuse bronchopneumonia; type 18A pneumococci were obtained in the sputum and blood cultures were negative. The illness in this case was complicated by cirrhosis of the liver, pulmonary tuberculosis, nitrogen retention in the blood, and congestive heart failure. The response of the pneumonia to penicillin was slow but the patient eventually recovered. In this case, the cold agglutinin titer was 20 both early and late in the disease. In the fourth case, the titer of streptococcal agglutinins obtained with each of the two strains during the acute phase was 10 and the titers during convalescence were 20 and 40 with strains 344 and E. S., respectively. This patient had typical lobar pneumonia; types 7 and 23 pneumococci were obtained from the sputum early in the disease; blood cultures were negative and the patient showed a good response to penicillin therapy. There were no cold agglutinins in any of his sera.

One of the cases of influenza is of particular interest. In this case, the illness began at the end of February 1944 and an influenza virus was isolated from throat washings obtained early in the course of the disease but this virus could not be identified as influenza $A$ or $B$. This was the only case of clinical influenza among a large number studied during that season (4) in which cold agglutinins developed. Cold hemagglutinins could not be demonstrated in the first two sera obtained in this case during the acute phase of the disease but they appeared during convalescence and reached a maximum titer of 80 . Weak agglutination for both strains of indifferent streptococci was obtained in a titer of 40 in the acute phase sera and stronger agglutination occurred in the convalescent sera in the same titer with strain E. S. and in a titer of 80 with strain 344 . There were a few râles heard in the lungs of this patient during the febrile period but $x$-rays were negative. It is possible that this represents a mild case of primary atypical pneumonia.

One additional case is of interest because of the occurrence of cold agglutinins. In this case, a cold hemagglutinin titer of 160 was obtained both in acute and convalescent sera but agglutinins were not demonstrated either for strain 344 or for strain E. S. This was a case of lobar pneumonia in which type 7 pneumococci were obtained from the sputum, blood cultures were negative, and the patient responded favorably to penicillin therapy. In this case, however, there was a history of severe cough of 3 weeks' duration prior to the abrupt onset of the symptoms of lobar pneumonia. This was the only case of bacterial pneumonia in which cold agglutinins were demonstrated in any significant titer.

\section{CORRELATION OF STREPTOCOCCAL AND COLD HEMAGGLUTININ TITERS}

There was some correlation, though not a very close one, between the maximum titers of cold isohemagglutinins and the maximum titers of agglutinins for the two strains of indifferent streptococci. The correlation was somewhat better with strain E.S. than with strain 344 . In individual sera, there were wide discrepancies between the titers of cold agglutinins and of the streptococcal agglutinins. There were some instances in which relatively high titers of streptococcal agglutinins were noted in sera with only low or moderate titers of cold agglutinins and others in which low titers of streptococcal agglutinins were obtained in sera which had cold agglutinins in high titer. The titers obtained with the two strains of indifferent streptococcus, however, were in much closer agreement. In general, the titers were higher in the cases of atypical pneumonia with strain E.S. than with strain 344 . On the other hand, agglutinins with strain E.S. were observed more frequently during the acute stage of the disease. In the sera of cases other than atypical pneumonia, the titers obtained with the two strains were more nearly identical. A better idea of the relation of the cold agglutinin titers and the titers for strains 344 and E.S. to each other and to the course of the disease in cases of atypical pneumonia may be had from the data shown in Table II.

Cross absorption tests were done in a few of the sera which showed both cold hemagglutinins and agglutinins for the indifferent streptococci. The results were uniform and corresponded to those reported by others (1). Absorption at $37^{\circ} \mathrm{C}$. with strain 344 completely removed the agglutinins for this strain and for E.S. but left the cold hemagglutinin titers intact. The same was true when strain E.S. was used. Absorption in the cold with human $\mathrm{O}$ cells removed the cold hemagglutinins but left the agglutinins for the two strains of streptococci unaffected.

\section{RELATION OF AGGLUTININS FOR INDIFFERENT STREPTOCOCCI TO HEMOLYTIC STREPTO- COCCAL INFECTIONS AND TO THE ANTI- STREPTOLYSIN TITER OF THE SERUM}

Through the courtesy of Dr. T. Duckett Jones, many of the sera used in the present study were tested for their content of antistreptolysin. There was little difference in the streptococcal agglutinin titers obtained in the cases of rheumatic fever 
TABLE II

Comparison of cold isohemagglutinin titers and titers of agglutinins for two strains of indifferent streptococci in selected cases of primary atypical preumonia of unknown etiology

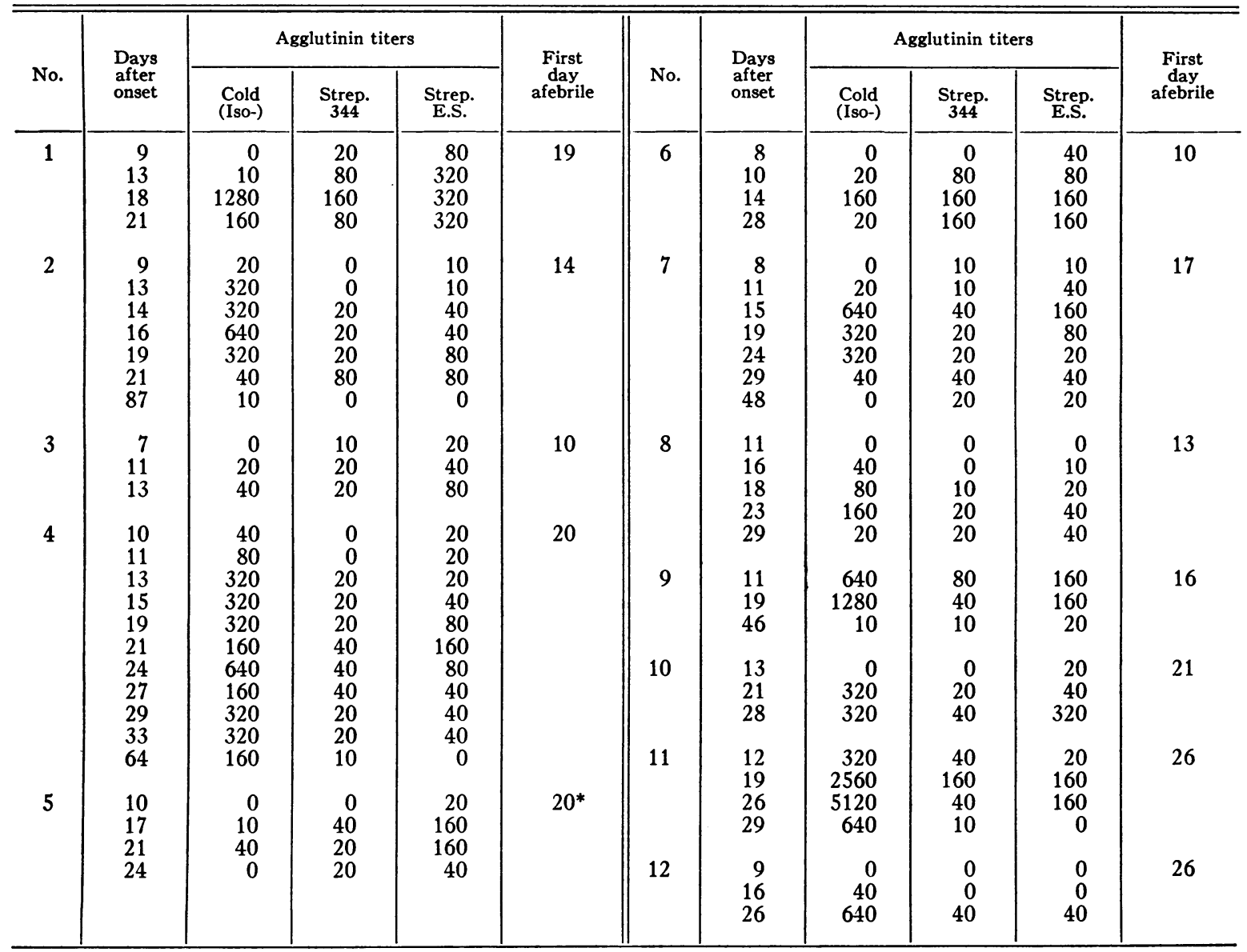

* Relapse of fever on day 21, died of hemolytic streptococcal superinfection on the 24th day.

In this table, titer $0=<10$ (the lowest dilution tested).

See also Figures 4 to 7 -in paper II of this series for additional cases.

and in the non-rheumatic subjects, irrespective of whether or not they were carriers of hemolytic streptococci. Furthermore, there were no differences in titers of agglutinins for each of the strains of indifferent streptococci in sera having a high titer of antistreptolysin and in those with low titers of the latter. In the cases of atypical pneumonia, as in those of other diseases not associated with hemolytic streptococci, no significant titers or rises in titers of antistreptolysin occurred. This was true both in sera in which agglutinins for the indifferent streptococci developed and in those in which such agglutinins failed to appear. A few isolated sera obtained in various stages of the disease showed unusually high titers of antistreptolysin. In almost every instance, these sera were heavily contaminated, usually with putrifying bacteria.

\section{RESULTS IN CASES OF HEMOLYTIC ANEMIA}

In a previous paper of this series (5), sera of moderate or high cold hemagglutinin titer were subjected to a variety of adsorbing agents and to filtration through various types of bacterial filters. Some of these procedures removed the cold agglutinins from the sera, either entirely or in part. Some of these sera were obtained from cases of atypical pneumonia and others from cases of hemolytic anemia. No differences were discerned in the behaviour of the sera obtained from these two types of cases with respect to the effect of these procedures. In the present study are included 
sera from 4 cases of hemolytic anemia in which the cold agglutinin titers ranged from 40 to 2560 . All of these sera failed to show any agglutinins for either of the two strains of indifferent streptococci. These findings suggest that agglutination with these streptococci may serve as an aid in differentiating two types of hemolytic anemia, one resulting from atypical pneumonia and the other independent of that disease. This differentiation is not an absolute one, however, since there were a small number of cases of atypical pneumonia in which the cold hemagglutinin titers ranged from 160 to 2560 and agglutinins for both strain 344 and $\mathrm{E}$. S. were absent or occurred only in a titer of 10 .

\section{DISCUSSION}

The serological findings previously reported (1) have been corroborated for the most part. As compared with these observations, however, agglutination with strain 344 occured with greater frequency in the acute phase of atypical pneumonia, in normal individuals and in the cases of other infections included in the present study. Among the cases of atypical pneumonia, a significantly greater proportion had titers of 10 or 20 than were found in other conditions. Titers of 40 or higher were limited mostly to the sera from cases of atypical pneumonia. Moreover, the development of agglutinins for streptococcus 344 in the course of the disease and the occurrence of significant rises in titer were also limited almost entirely to the cases of atypical pneumonia. The results of the tests in which strain $\mathrm{E}$. S. was used were, in general, parallel to those obtained with strain 344. The former was agglutinated in higher titers in many of the cases of atypical pneumonia. With strain E. S., however, agglutination occurred more often in the acute phase sera of some of the atypical pneumonias. In sera from cases other than atypical pneumonia, the agglutinations obtained with the two strains were more nearly alike.

Strain E. S. was obtained with ease because it occurred in almost pure culture and was recognized and identified from a routine culture made from sputum on the surface of a blood agar plate. No systematic attempt was made to isolate strains of indifferent streptococci from other cases of atypical pneumonia or of other conditions. Histo-. logical studies of the lungs in fatal cases, however, failed to reveal any evidence that such an organism plays any part in the disease.

Several features of the data presented are worth mentioning. In the first place, the sera in the cases of atypical pneumonia had all been stored for several months before the streptococcal agglutination tests were carried out. Sera from the remaining cases on the other hand, were either fresh or only a few weeks old when they were tested. The cold hemagglutinin titers had definitely deteriorated and to a considerable extent in a larger proportion of these sera (6). It is possible that the streptococcal agglutinins had also deteriorated to some extent in the serum of the cases of atypical pneumonia. If that is so, then the titers of agglutinins for the indifferent streptococci in the cases of atypical pneumonia may have been higher than those recorded. The differences between the titers obtained in atypical pneumonias and in other conditions would then be correspondingly greater.

On the other hand, the cases of atypical pneumonia are not entirely representative. ${ }^{1}$ They include only cases in which cold agglutinins were present. Sera from cases in which cold agglutinins did not develop were unfortunately not available for this study. The occurrence of agglutinins for indifferent streptococci in characteristic cases of atypical pneumonia in which cold hemagglutinins do not develop cannot be stated from this study. The results of the cold agglutinin studies previously reported (3) and the correlations of the streptococcal and the cold hemagglutinin titers suggest that agglutination with the indifferent streptococci would probably develop less frequently and in lower titers in cases of atypical pneumonia in which cold hemagglutinins do not develop. The significance of the present findings, like those of the cold agglutinins, is a matter for speculation. The results reported in this paper, as well as those reported by others (1), indicate some relationship between these indifferent streptococci and primary atypical pneumonia but, as

\footnotetext{
1 Characteristic cases of primary atypical pneumonia were encountered only rarely during the winter of 1943-44. Only stored sera were, therefore, available from such cases for this study.
} 
those authors have pointed out, they cannot be interpreted as indicating an etiological rôle for these streptococci. The findings, however, do suggest a possible antigenic relationship between the causative agent of primary atypical pneumonia, of these indifferent streptococci and of human erythrocytes. The results of the absorption tests suggest further that the antigen which these streptococci have in common with the unknown agent of atypical pneumonia is different from that which the latter shares with human red blood cells. It is possible, however, that the indifferent streptococcus coexists as a non-pathogen which becomes antigenic in atypical pneumonia.

One point which has emerged from the present studies is of interest and may have a limited significance from a hematological point of view. Cases may be encountered in which hemolytic anemia is discovered but the antecedent history is difficult to interpret. The present findings, though they are based on a limited number of cases, suggest that agglutination with strains of indifferent streptococci similar to 344 may serve as an aid in differential diagnosis. Agglutination of these strains in the serum of such cases would strongly suggest atypical pneumonia as the predisposing factor or antecedent illness in such a case. Failure to demonstrate such agglutinins would tend to rule out this possibility, but will not definitely exclude it.

\section{SUMMARY AND CONCLUSION}

Sera obtained from 78 cases of atypical pneumonia and from 163 other persons, including normal subjects and patients with various types of streptococcal disease and of other respiratory infections, were tested for agglutination with the indifferent streptococcus 344 and with a similar strain isolated from the sputum of a case of atypical pneumonia. In conditions other than atypical pneumonia, maximum titers of 10 or 20 were obtained with either strain in about one-third of the cases and higher titers were obtained in only 5 per cent or less. In cases of primary atypical pneumonia, on the other hand, only a few failed to show agglutination with these strains, while one-half of the patients developed maximum titers of 40 or higher for strain 344 and three-fourths of the patients developed agglutinins in such titers for strain E. S.

There was some correlation, though not a very close one, between the maximum cold isohemagglutinin titers and the maximum titers of agglutinins obtained with the two strains of indifferent streptococci. Cross absorption tests indicate that these two kinds of agglutinins are unrelated.

There was no correlation whatever between the titers of cold hemagglutinins or of the agglutinins for the indifferent streptococci and the antistreptolysin titers of the sera. This was true both in the cases of atypical pneumonia and in those of hemolytic streptococcal infections.

The agglutination of indifferent streptococci similar to those used in this study may serve as an aid in the differential diagnosis of certain cases of hemolytic anemia.

\section{BIBLIOGRAPHY}

1. Thomas, L., Mirick, G. S., Curnen, E. C., Ziegler, J. E., Jr., and Horsfall, F. L., Jr., Serological reactions with an indifferent streptococcus in primary atypical pneumonia. Science, 1943, 98, 566.

2. Thomas, L., Curnen, E. C., Mirick, G. S., Ziegler, J. E., and Horsfall, F. L., Jr., Complement fixation with dissimilar antigens in primary atypical pneumonia. Proc. Soc. Exper. Biol. and Med., 1943, $52,121$.

3. Finland, M., Peterson, O. L., Allen, H. E., Samper, B. A., and Barnes, M. W., Cold agglutinins. II. Cold isohemagglutinins in primary atypical pneumonia of unknown etiology with a note on the occurrence of hemolytic anemia in these cases. J. Clin. Invest., 1945, 24, 458.

4. Finland, M., Barnes, M. W., and Samper, B. A., Influenza virus isolations and serological studies made in Boston during the winter of 1943-1944. J. Clin. Invest., 1945, 24, 192.

5. Finland, M., Peterson, O. L., and Barnes, M. W., Cold agglutinins. III. Observations on certain serological and physical features of cold agglutinins in cases of primary atypical pneumonia and of hemolytic anemia. J. Clin. Invest., 1945, 24, 474.

6. Finland, M., and Barnes, M. W., Cold agglutinins. V. Deterioration of cold isohemagglutinins on storage. J. Clin. Invest., 1945, 24, 490. 